\title{
Assessing the impacts of agricultural managements on soil carbon stocks, nitrogen loss and crop production — a modelling study in Eastern Africa
}

\author{
Jianyong Ma ${ }^{1}$, Sam S. Rabin ${ }^{1,2}$, Peter Anthoni ${ }^{1}$, Anita D. Bayer ${ }^{1}$, Sylvia S. Nyawira ${ }^{3}$, Stefan Olin ${ }^{4}$, Longlong \\ $\mathrm{Xia}^{1}$, Almut Arneth ${ }^{1,5}$ \\ ${ }^{1}$ Institute of Meteorology and Climate Research-Atmospheric Environmental Research, Karlsruhe Institute of Technology, 82467 \\ Garmisch-Partenkirchen, Germany \\ ${ }^{2}$ Department of Environmental Sciences, Rutgers University, New Brunswick, 08901 NJ, USA \\ ${ }^{3}$ International Center for Tropical Agriculture (CIAT), ICIPE Duduville Campus, P O Box 823-00621 Nairobi, Kenya \\ ${ }^{4}$ Department of Physical Geography and Ecosystems Science, Lund University, 22362 Lund, Sweden \\ ${ }^{5}$ Institute of Geography and Geoecology, Karlsruhe Institute of Technology, 76131 Karlsruhe, Germany \\ Correspondence to: Jianyong Ma (Jianyong.ma@kit.edu)
}



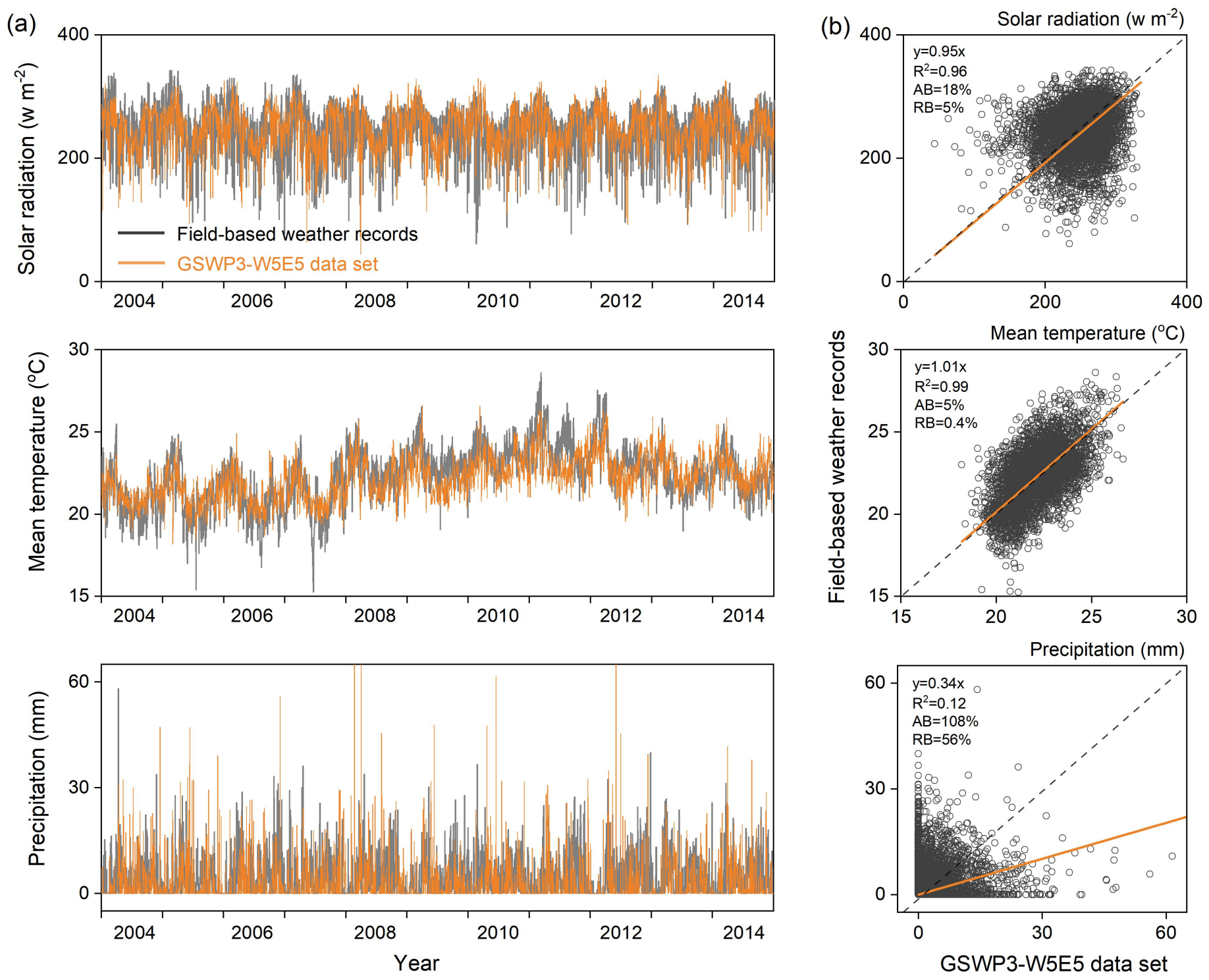

Figure S1. Comparison of daily climate between GSWP3-W5E5 data set $\left(34.25^{\circ} \mathrm{E}, 0.25^{\circ} \mathrm{N}\right)$ and field-based weather records at Kenyan INM3 site $\left(34.40^{\circ} \mathrm{E}, 0.14^{\circ} \mathrm{N}\right)$ from $2004-2014$ as time series (a), and scatter plots shown in (b). $\mathrm{AB}$ and $\mathrm{RB}$ are mean absolute bias and relative bias, respectively, presented in percent $(\%)$. 
Following Olin et al. (2015), relationships between allocation to sorghum leaves $\left(\mathrm{P}_{\text {leaf }}\right)$, stem $\left(\mathrm{P}_{\text {stem }}\right)$, root $\left(\mathrm{P}_{\text {root }}\right)$, and grains $\left(\mathrm{P}_{\text {yield }}\right)$ based on the allocation model of Penning de Vries et al. (1989) are established using a logistic growth function, a Richards curve (Richards, 1959) (Eq. S1):

$f_{i}=a_{i}+\frac{b_{i}-a_{i}}{1+e^{-C_{i} \times\left(D S-d_{i}\right)}}$

where $D S$ is crop development stage, ranging from 0 to $2(D S=0$, sowing; $D S=1$, flowering; $D S=2$, harvest $)$; and $\mathrm{a}_{\mathrm{i}}, \mathrm{b}_{\mathrm{i}}, \mathrm{c}_{\mathrm{i}}, \mathrm{d}_{\mathrm{i}}$ are fitting coefficients for the three functions (specific values given in Table S1 below).

The relative relationships of daily assimilate allocation to the organs are described by Eqs. S2:

$f_{1}=\frac{P_{\text {root }}}{P_{\text {veg }}}, f_{2}=\frac{P_{\text {leaf }}}{P_{\text {veg }}-P_{\text {root }}}, f_{3}=\frac{P_{\text {yield }}}{P_{\text {veg }}+P_{\text {yield }}}, P_{\text {veg }}+P_{\text {yield }}=1$

where $P_{v e g}$ are the fraction of carbon allocated to vegetative organs (i.e., $P_{\text {veg }}=P_{\text {leaf }}+P_{\text {stem }}+P_{\text {yield }}$ ), ranging from 0 to 1 .

We can achieve dynamic carbon allocation to the plant organs over the growing season by combining Eqs. S2:

$\left\{\begin{array}{l}P_{\text {root }}=f_{1} \times\left(1-f_{3}\right) \\ P_{\text {leaf }}=f_{2} \times\left(1-f_{1}\right) \times\left(1-f_{3}\right) \\ P_{\text {stem }}=P_{\text {veg }}-P_{\text {root }}-P_{\text {leaf }}=\left(1-f_{1}\right) \times\left(1-f_{2}\right) \times\left(1-f_{3}\right) \\ P_{\text {yield }}=f_{3}\end{array}\right.$

Partitioning functions are plotted for sorghum in Fig. S2. More details on how these relationships were derived can be found in Olin et al. (2015).

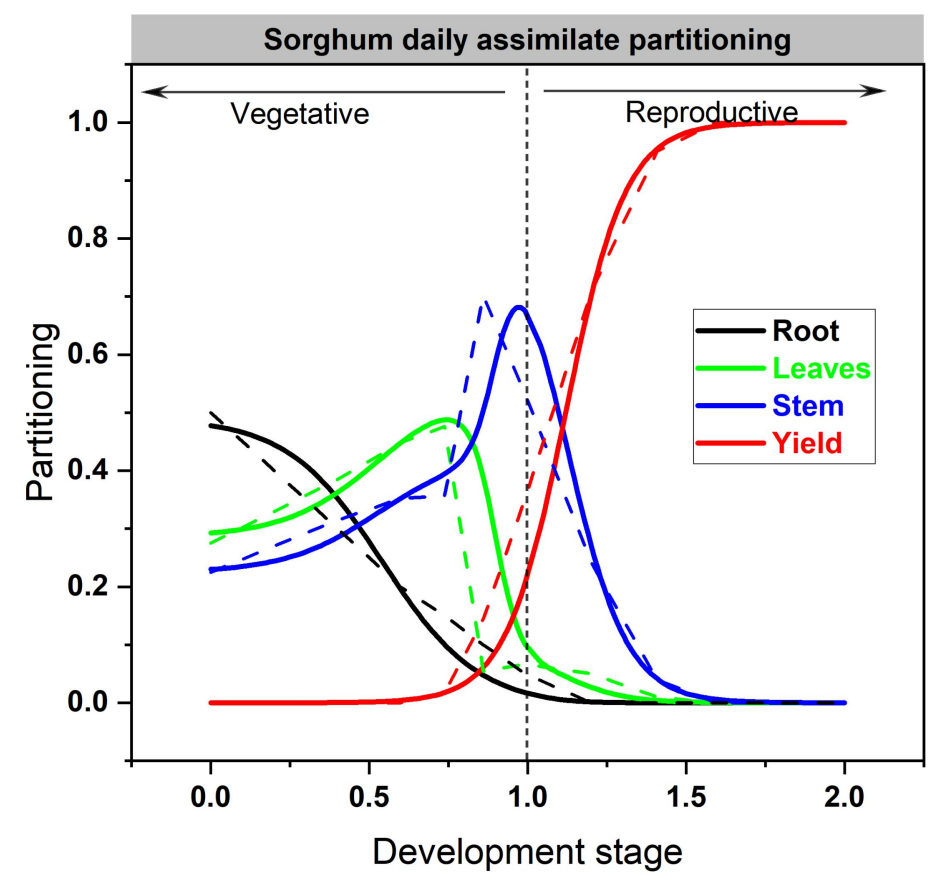

Figure S2. The organ's assimilate partitioning to roots, leaves, stem, and yields for sorghum. Solid lines represent the fitted Richards functions used in this study, and dashed lines are the allocation scheme from Penning de Vries et al. (1989). 
Table S1. CFT-specific parameters for the daily carbon allocation (Eqs. S1-S3), specific leaf area (SLA), minimum C:N value of the leaves (leaf $\mathrm{C}: \mathrm{N}_{\min }$ ), and the fraction of the total mineral $\mathrm{N}$ applied at the three crop development stages (DS, in which DS=0, sowing; DS=0.5, halfway through the vegetative stage; $\mathrm{DS}=1.0$, flowering).

\begin{tabular}{|c|c|c|c|c|c|c|c|c|}
\hline Parameter & & Maize I $^{\text {I }}$ & Sorghum II & Spring wheat ${ }^{I}$ & Rice I $^{\mathrm{I}}$ & Pulses III & Soybean III & Unit \\
\hline \multirow{4}{*}{$f_{1}$} & $\mathrm{a}_{1}$ & 0.24 & 0.49 & 0.62 & 0.14 & 0.59 & 0.56 & \\
\hline & $b_{1}$ & 1.22 & 0 & -0.02 & -2.45 & 0 & 0 & \\
\hline & $\mathrm{c}_{1}$ & 18.1 & 6.74 & 5.80 & 2.79 & 5.53 & 3.74 & \\
\hline & $\mathrm{d}_{1}$ & 1.12 & 0.54 & 0.55 & 2.19 & 0.51 & 0.53 & \\
\hline \multirow{4}{*}{$\mathrm{f}_{2}$} & $\mathrm{a}_{2}$ & 0.68 & 0.56 & 0.86 & 0.52 & 0.75 & 0.67 & \\
\hline & $b_{2}$ & -0.06 & 0.09 & 0.19 & -0.04 & 0 & 0 & \\
\hline & $\mathrm{c}_{2}$ & 12.48 & 25.75 & 28.65 & 10.16 & 7.69 & 30.78 & \\
\hline & $\mathrm{d}_{2}$ & 0.81 & 0.90 & 0.55 & 0.79 & 1.38 & 1.73 & \\
\hline \multirow{4}{*}{$f_{3}$} & $\mathrm{a}_{3}$ & 0 & 0 & 0 & 0 & 0 & 0 & \\
\hline & $b_{3}$ & 1 & 1 & 1 & 1 & 1 & 1 & \\
\hline & $c_{3}$ & 28.52 & 10.54 & 8.27 & 121.21 & 9.59 & 8.93 & \\
\hline & $\mathrm{d}_{3}$ & 1.03 & 1.12 & 1.10 & 1.09 & 1.46 & 1.41 & \\
\hline SLA & & 45 & 45 & 35 & 45 & 45 & 40 & $\mathrm{~m}^{2} \mathrm{~kg}^{-1} \mathrm{C}^{-1}$ \\
\hline Leaf C: $\mathrm{N}_{\min }$ & & 15 & 15 & 15 & 10 & 10 & 8 & $\mathrm{~kg} \mathrm{C} \mathrm{kg} \mathrm{N}^{-1}$ \\
\hline $\mathrm{N}_{\mathrm{app}}, \mathrm{DS}=0$ & & $11 \%$ & $11 \%$ & $11 \%$ & $3 \%$ & $50 \%$ & $50 \%$ & fraction \\
\hline $\mathrm{N}_{\mathrm{app}}, \mathrm{DS}=0.5$ & & $50 \%$ & $50 \%$ & $50 \%$ & $46 \%$ & $0 \%$ & $0 \%$ & fraction \\
\hline $\mathrm{N}_{\text {app }}, \mathrm{DS}=1.0$ & & $39 \%$ & $39 \%$ & $39 \%$ & $51 \%$ & $50 \%$ & $50 \%$ & fraction \\
\hline
\end{tabular}

${ }^{\text {I }}$ Olin et al. (2015); ${ }^{\text {II }}$ This study; ${ }^{\text {III }}$ Ma et al. (2021) 

(a) crop areas (ha)
(b) $\mathrm{N}$ fertilizer inputs $\left(\mathrm{kg} \mathrm{N} \mathrm{ha}^{-1}\right)$
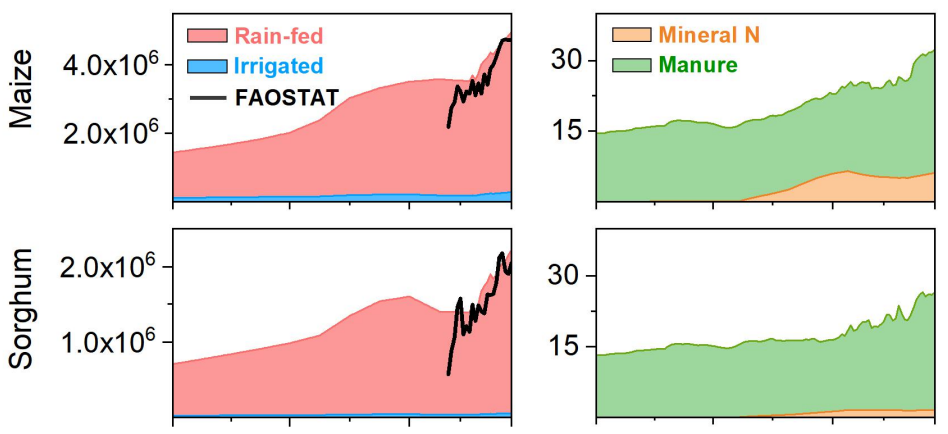

(c) Mean temperature and $\mathrm{CO}_{2}$ concentration
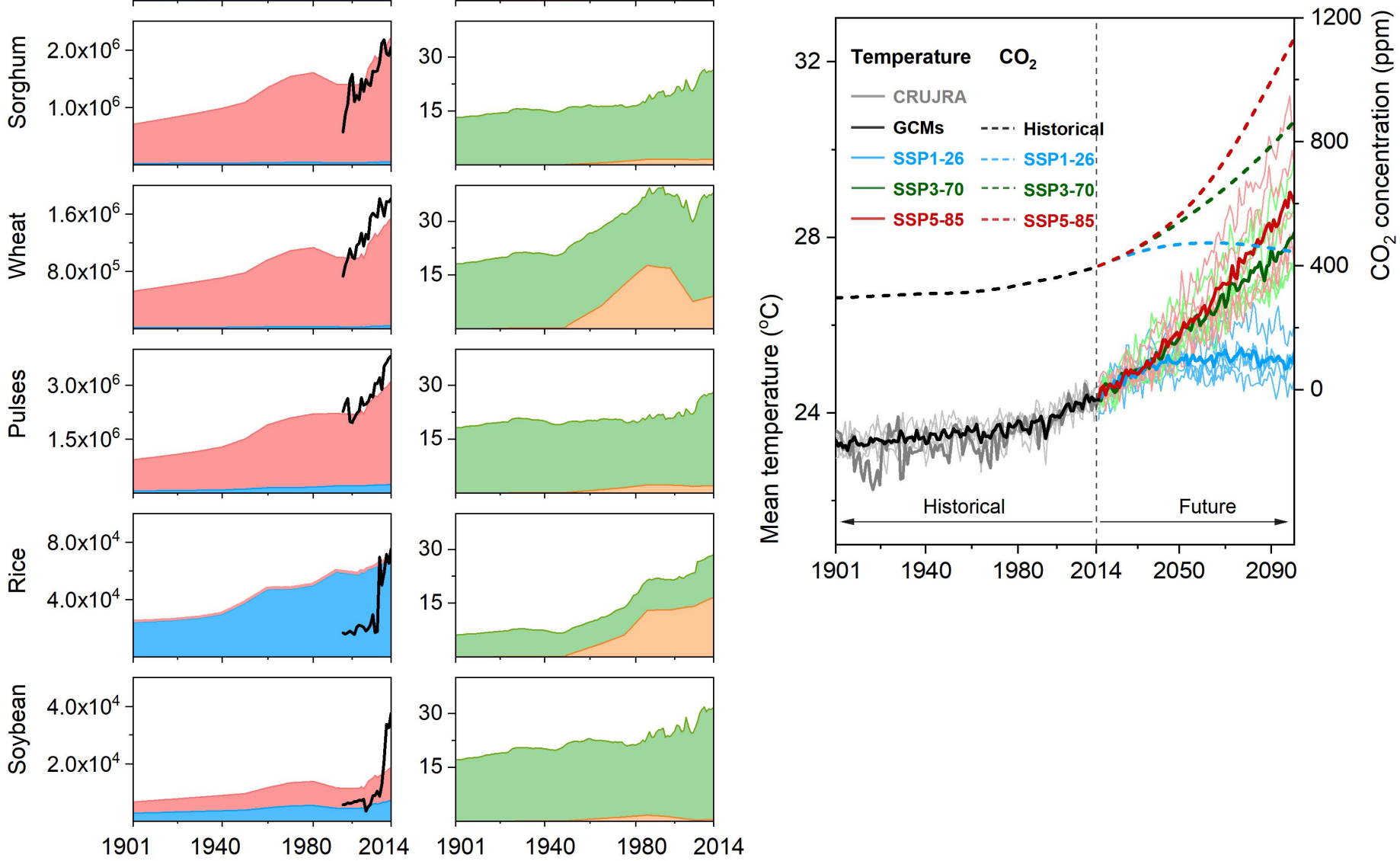

Figure S3. Inputs used for simulations in Eastern Africa: (a) simulated crop-specific areas (rain-fed and irrigated) over the historic period compared to statistics from FAO (ha); (b) mean rates of mineral $\mathrm{N}$ fertilizer and manure applied to each crop type (kg N ha-1) from 1901-2014; (c) annual $\mathrm{CO}_{2}$ concentration (ppm, right scale), and mean temperature $\left({ }^{\circ} \mathrm{C}\right.$, left scale) from CRUJRA (Sect. 2.3.2) and five GCMs (Sect. 2.3.3). The black, blue, green, and red thick solid lines in (c) denote the temperature averaged by five GCMs for historical, SSP1-26, 3-70 and 5-85 scenarios, respectively; thin lines in light color represent the temperature from individual GCM. Dashed lines show $\mathrm{CO}_{2}$ concentrations. 

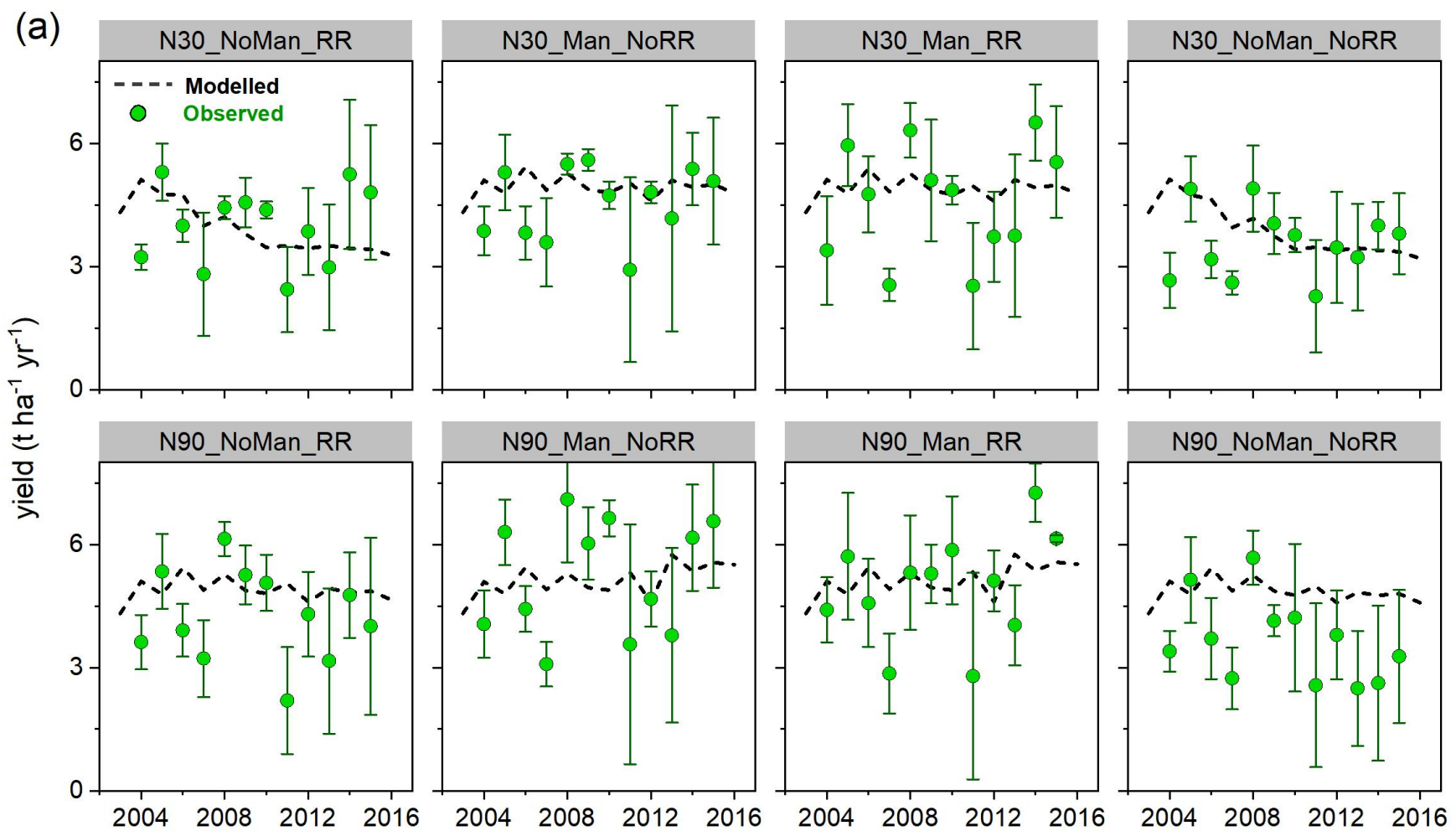

(b)
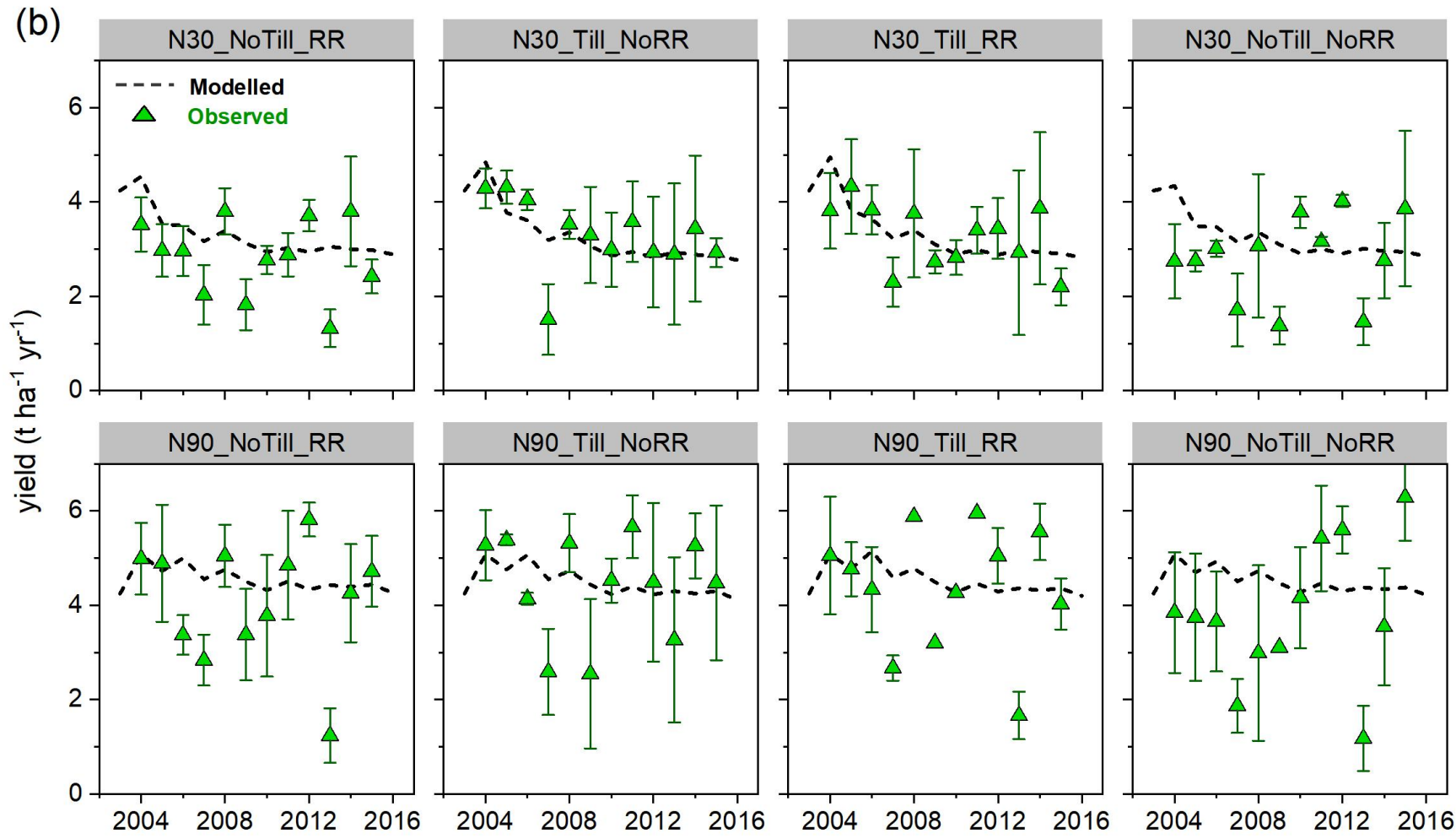

Figure S4. Modelled and observed maize yields (long rainy season, i.e. the main growing period) for the evaluation treatments at INM3 (a) and CT1 (b) sites, with two levels of mineral N fertilizer input (N30 and N90). The dashed line is the modelled yields, and the closed circle represents the observed value averaged by the four replicates in the trials, with standard deviation as given in the vertical bar. 
Table S2. Evaluation of the model performance to simulate maize yields in long rainy season $(\mathrm{n}=12)$ using multi-years average, absolute bias (AB), root mean square error (RMSE), and Person correlation coefficient ( $r$ ) at INM3 and CT1 sites.

\begin{tabular}{|c|c|c|c|c|c|}
\hline Treatment & $\begin{array}{l}\text { Observed mean } \\
\quad\left(\mathrm{t} \mathrm{ha}^{-1} \mathrm{yr}^{-1}\right)\end{array}$ & $\begin{array}{l}\text { Simulated mean } \\
\left(\mathrm{t} \mathrm{ha}^{-1} \mathrm{yr}^{-1}\right)\end{array}$ & $\begin{array}{l}\mathrm{AB} \\
(\%)\end{array}$ & $\begin{array}{c}\text { RMSE } \\
\left(\mathbf{t ~ h a}^{-1} \mathbf{y r}^{-1}\right)\end{array}$ & $r$ \\
\hline \multicolumn{6}{|l|}{ INM3 } \\
\hline N30_NoMan_RR & 4.00 & 3.95 & 26 & 1.08 & $0.02(p>0.05)$ \\
\hline N90_NoMan_RR & 4.25 & 4.95 & 32 & 1.31 & $0.07(p>0.05)$ \\
\hline N30_Man_NoRR & 4.56 & 4.98 & 21 & 1.01 & $0.27(p>0.05)$ \\
\hline N90_Man_NoRR & 5.19 & 5.16 & 28 & 1.41 & $-0.06(p>0.05)$ \\
\hline N30_Man_RR & 4.58 & 4.96 & 33 & 1.37 & $0.14(p>0.05)$ \\
\hline N90_Man_RR & 4.95 & 5.17 & 27 & 1.32 & $-0.03(p>0.05)$ \\
\hline N30_NoMan_NoRR & 3.56 & 3.91 & 26 & 1.04 & $0.05(p>0.05)$ \\
\hline N90_NoMan_NoRR & 3.65 & 4.92 & 46 & 1.59 & $0.23(p>0.05)$ \\
\hline \multicolumn{6}{|l|}{ CT1 } \\
\hline N30_NoTill_RR & 2.83 & 3.27 & 34 & 0.88 & $0.30(p>0.05)$ \\
\hline N90_NoTill_RR & 4.10 & 4.59 & 39 & 1.28 & $0.13(p>0.05)$ \\
\hline N30_Till_NoRR & 3.31 & 3.26 & 17 & 0.61 & $0.59(p<0.05)$ \\
\hline N90_Till_NoRR & 4.41 & 4.53 & 24 & 1.04 & $0.17(p>0.05)$ \\
\hline N30_Till_RR & 3.28 & 3.31 & 17 & 0.62 & $0.53(p<0.05)$ \\
\hline N90_Till_RR & 4.37 & 4.58 & 32 & 1.26 & $0.18(p>0.05)$ \\
\hline N30_NoTill_NoRR & 2.81 & 3.22 & 43 & 1.07 & $-0.12(p>0.05)$ \\
\hline N90_NoTill_NoRR & 3.78 & 4.54 & 58 & 1.66 & $-0.15(p>0.05)$ \\
\hline
\end{tabular}



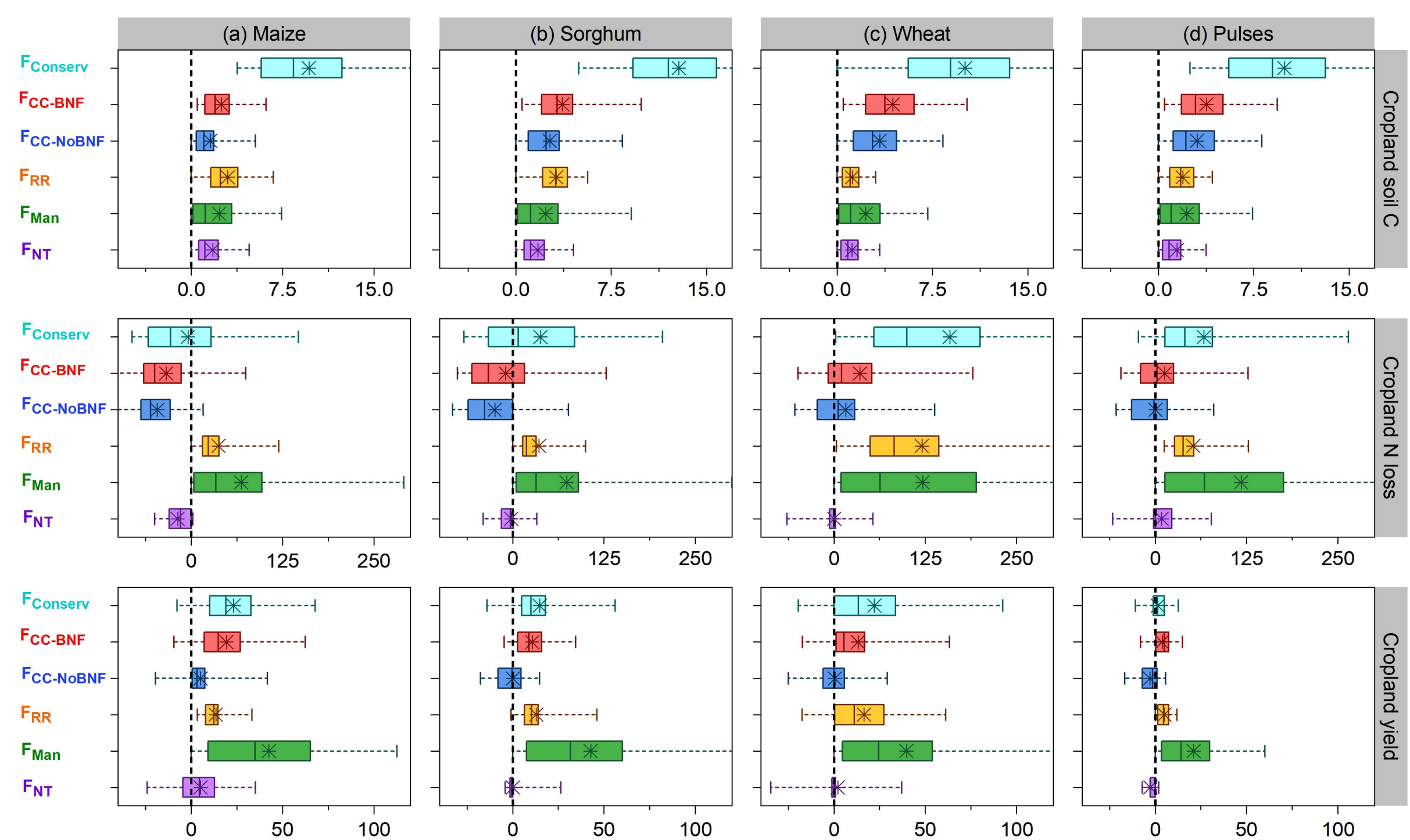

Relative change to standard management $\left(\mathrm{F}_{\text {std }}\right)(\%)$

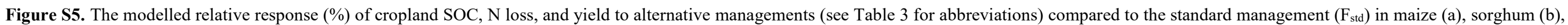

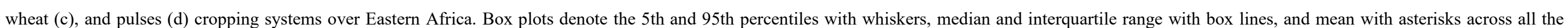
simulated crop grid cells (maize-403; sorghum-398; wheat-382; pulses-425). 
(a) Maize

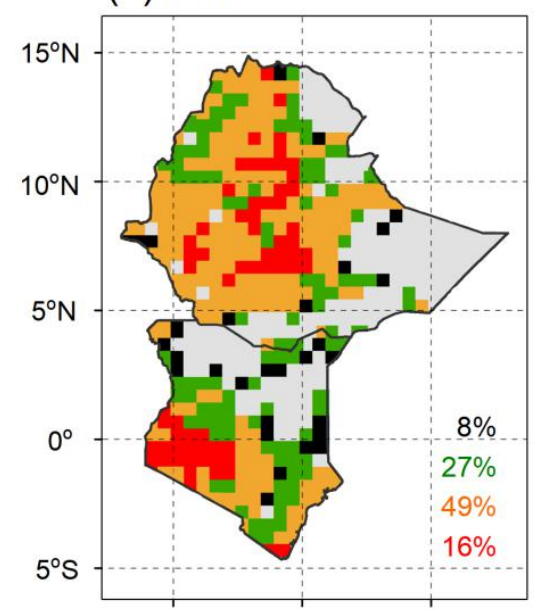

(c) Wheat

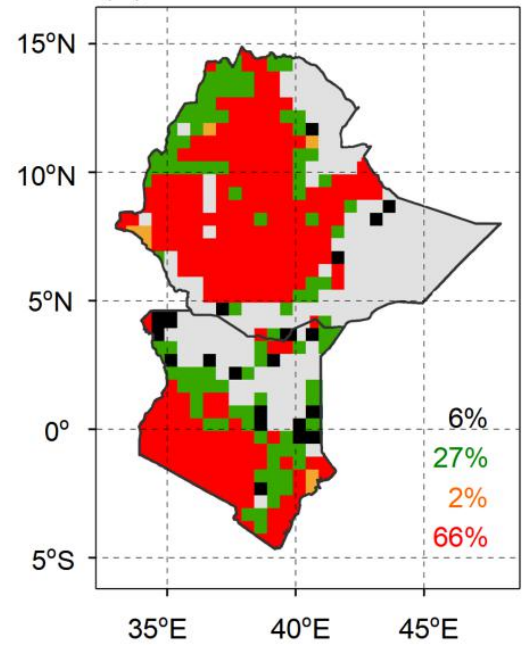

(b) Sorghum

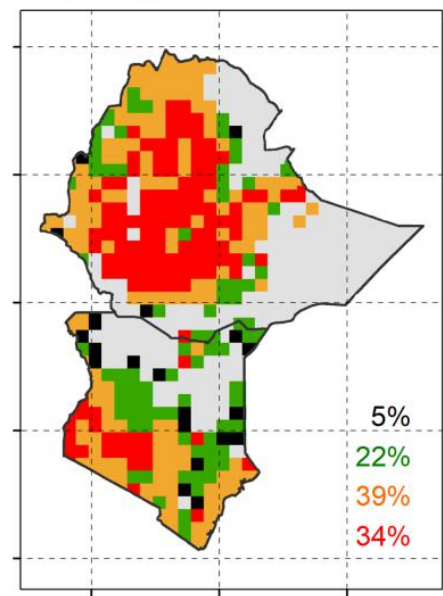

(d) Pulses

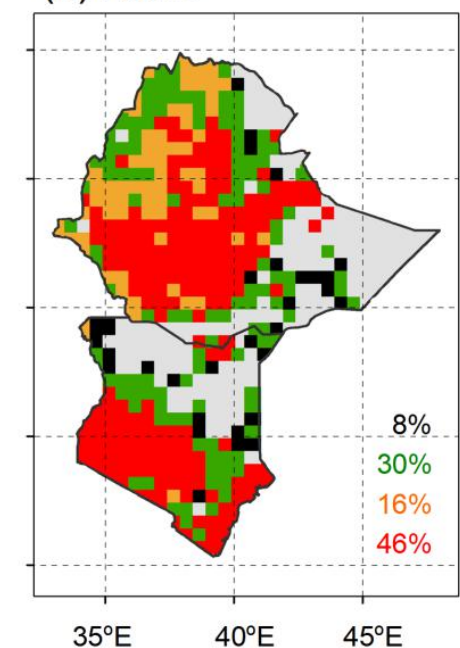

Non-crop

- $\mathrm{F}_{\text {std }}$

$\square \mathrm{F}_{\text {Man }}$

$\square \mathrm{F}_{\mathrm{RR}}$

$\square$ FCC-BNF

Figure S6. The optimal $\mathrm{C}$ sequestration practice ( $\mathrm{F}_{\mathrm{opt}}$, Eq.4) simulated by LPJ-GUESS in maize (a), sorghum (b), wheat (c), and pulses (d) cropping systems in Kenya and Ethiopia (B2, Table 1). Numbers in plots represent the grid cell proportion of each optimal management to the total crop grid cells (maize-403; sorghum-398; wheat-382; pulses-425). The standard management ( $\mathrm{F}_{\text {std, }}$ black in plots) was chosen when none of other alternative managements yielded a net increase in SOC. See table 3 for management abbreviations. 
(a)
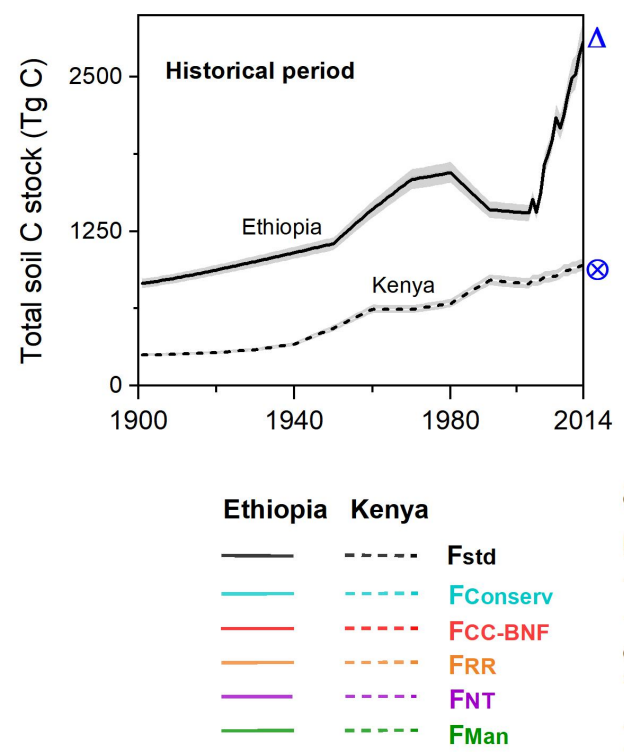
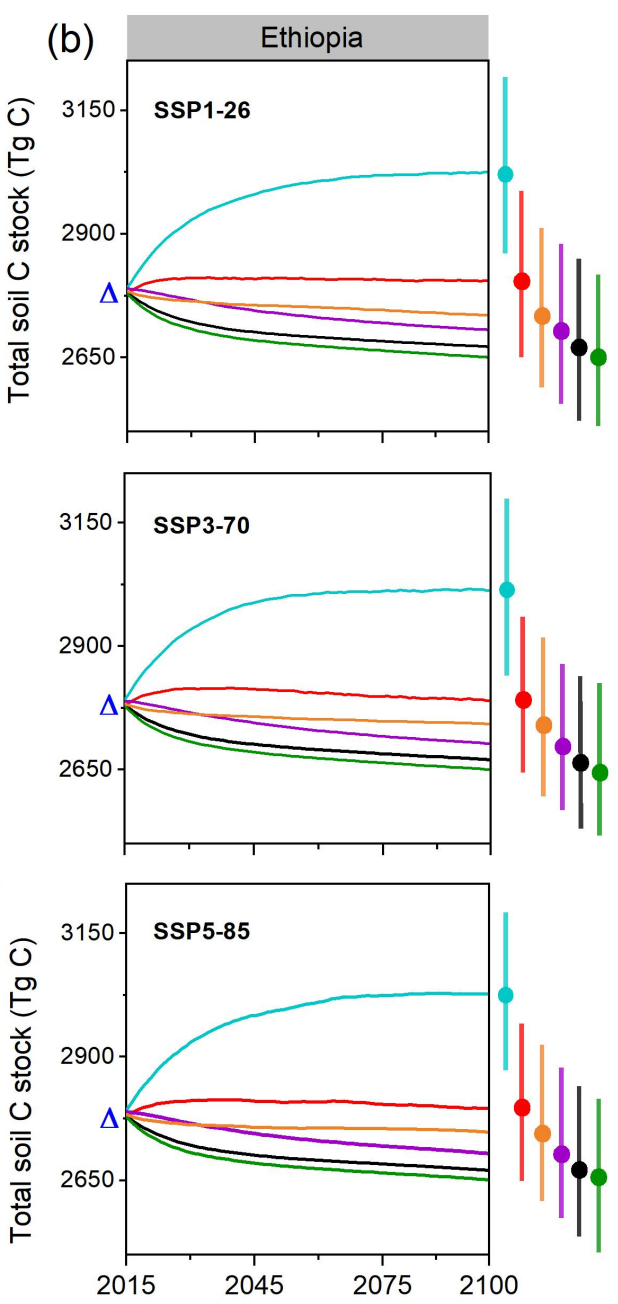
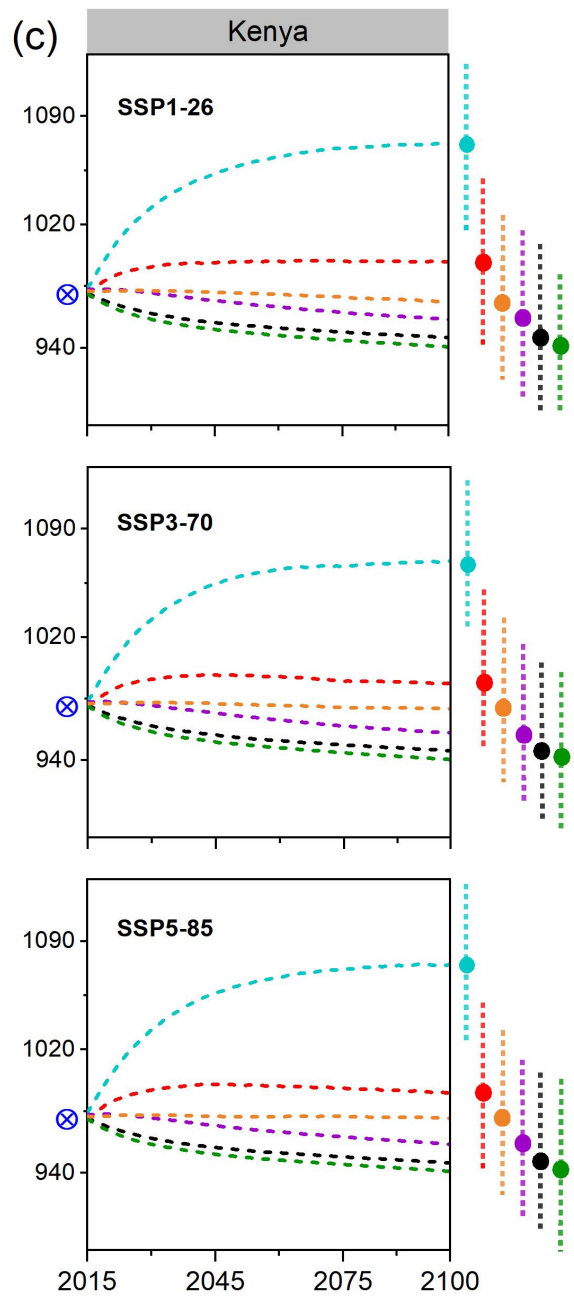

Figure S7. The simulated cropland soil $\mathrm{C}$ stocks from the standard management $\left(\mathrm{F}_{\text {std }}\right)$ for GCM-based historical period (C1, Table 1) (a), and SOC potential response to alternative management options with future SSP1-26, 3-70 and 5-85 scenarios (C2, Table 1) in Ethiopia (b) and Kenya (c). Blue triangle for Ethiopia and sun cross for Kenya denote the seamless connection between historical period and future simulations. Filled circle represents the averaged result between 2091 and 2100, with a range from five GCMs as given in vertical bar. See Table 3 for management abbreviations. 
Table S3. The relative (\%) number of cropland grid cell and areas regarding the potential transition of optimal C sequestration practice $\left(\mathrm{F}_{\mathrm{opt}}\right.$, Eq. 4), comparing the historical period (GCM-based climate; C3, Table 1) with three future SSP scenarios from 2091-2100 (C2, Table 1). See Table 3 for management abbreviations.

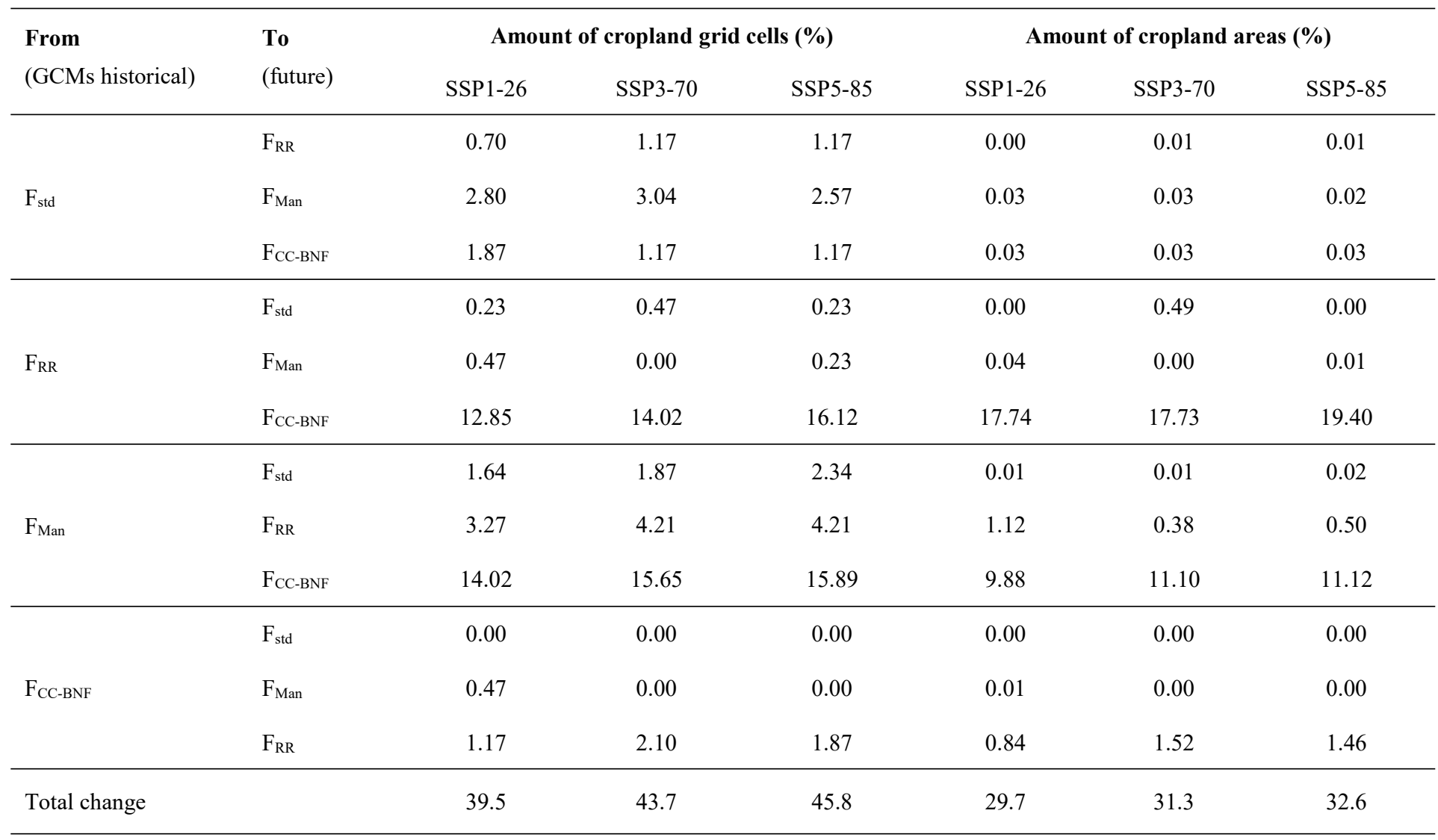




\section{Reference}

Ma, J., Olin, S., Anthoni, P., Rabin, S. S., Bayer, A. D. and Nyawira, S. S.: Modelling symbiotic biological nitrogen fixation in grain legumes globally by LPJ-GUESS, Geosci. Model Dev. Discuss., (September), 1-35, 2021.

Olin, S., Schurgers, G., Lindeskog, M., Wärlind, D., Smith, B., Bodin, P., Holmér, J. and Arneth, A.: Modelling the response of yields and tissue $\mathrm{C}: \mathrm{N}$ to changes in atmospheric CO2 and $\mathrm{N}$ management in the main wheat regions of western Europe, Biogeosciences, 12(8), 2489-2515, doi:10.5194/bg-12-2489-2015, 2015.

Penning de Vries, F. W. T., Jansen, D. M., Berge, H. F. M. ten and Bakema, A.: Simulation of ecophysiological processes of growth in several annual crops, Centre for Agricultural Publishing and Documentation, Wageningen, Wageningen., 1989.

Richards, F. J.: A flexible growth function for empirical use, J. Exp. Bot., 10(2), 290-301, doi:10.1093/jxb/10.2.290, 1959. 